\title{
TRANSINETI ANALYSIS OF PRESSURIZATION AND PNEUMATIC SUBSYSTEMS OF THE X-34 MAIN PROPULSION SYSTEM
}

\author{
A. Hedayat and K. C. Knight \\ Space Transportation Directorate \\ Sverdrup Technology, Inc. MSFC Group \\ Hunstville, AL 35806 \\ R. H. Champion Jr. \\ Space Transportation Directorate \\ Marshall Space Flight Center \\ Huntsville, AL 35812
}

\begin{abstract}
Transient models for the pressurization, vent/relief, and pneumatic subsystems of the X-34 Main Propulsion System are presented and simulation of their operation within prescribed requirements are provided. First, using ROCket Engine Transient Simulation (ROCETS) program, pressurization subsystem operation was simulated and helium requirements and the ullage thermodynamic condition within each propellant tank were calculated. Then, Overpressurization scenarios of propellant tanks and the response of vent/relief valves were evaluated using ROCETS simulation of simultaneous operation of the pressurization and vent/relief subsystems by incorporating the valves data into the model. Finally, the ROCETS simulation of in-flight operation of pneumatic subsystem predicted the overall helium consumption, Inter-Propellant Seal (IPS) purge flowrate and thermodynamic conditions, and Spin Start power.
\end{abstract}

\section{INTRODUCTION}

The X-34 is a single stage Liquid Oxygen (LOX) and Rocket propellant 1 (RP-1) fueled launch vehicle. The X-34 is carried for up to 2.5 hours in a horizontal captive carry mode. This is done without resupply of propellant. . The main thrust for the vehicle is provided by the MSFC developed FATRAC engine. It generates 60,000 lbf and 310 seconds of specific impulse. The engine has a single shaft pump. The X-34 vehicle uses the L-1011 as the first stage to carry it to launch altitude of $38,000 \mathrm{ft}$ for release. Once released, the FASTRAC engine ignites at 7 seconds, when it has reached a safe distance from L-1011. Then it transitions to vertical to exit the atmosphere. After burnout, the vehicle becomes a glider for reentry. In the case of an aborted engine ignition, the vehicle must dump the propellants to achieve landing weight. The Main Propulsion System (MPS) functions in the loading, storing, delivery, and disposing of propellant. The MPS includes the LOX and RP-1 feed, fill drain, dump, bleed, vent, relief, pressurization, and pneumatic subsystems. An overview description of the X-34 MPS has been provided by Sgarlata and 
Winters ${ }^{1}$ and Champion ${ }^{2}$. In addition, several X-34 MPS analyses are provided by Brown et. $\mathrm{al}^{3}$, Hedayat et. $\mathrm{al}^{4}$, and McDonald et. $\mathrm{al}^{5,6}$.

\section{PRESSURIZATION SUBSYSTEM ANALYSIS}

The pressurization system is used to transfer propellants from the tanks to the turbopump at the required flowrates and pressures. The pressurization system is required to provide sufficient helium in order to maintain the LOX and RP-1 tanks within the allowable operational range. A schematic of the pressurization system is shown in Figure 1 . The Gaseous Helium (GHe) is stored in 4 bottles at an initial pressure then it is supplied to the propellant tanks at limited flowrates using valves and regulators. In addition, solenoid valves control the pressurization of the LOX and RP-1 tanks within the allowable pressure range. Check valves are used to prevent any mixing of RP-1 and LOX, and to avoid the consequence damages. The pressurant is introduced into the tanks through a diffuser, which is designed to operate when submerged or dry. Helium is supplied to the propellant tanks through two regulators. During the pressurization process, the second regulator is considered to be completely open while the passage of the first regulator is adjusted such that the pressure at the exit is maintained at a specified value. Initially, the regulator set pressure was considered to be 350 psia but the test data indicated that for the set pressure of 350 psia, a regulator lockup of 401 psia was required. While a lockup of 350 psia provided a regulator set pressure of 314 psia. To perform analysis and to evaluate the performance of the system, three different regulator set pressures, 314,350 , and 401 psia were considered. In this analysis, the following assumptions were made:

1. Helium initial temperature and pressure at ground loading are $530^{\circ} \mathrm{R}$ and 5000 psia.

2. LOX temperature is $163^{\circ} \mathrm{R}$. LOX tank ullage pressure is 65 psia with a \pm 3 psi control range.

3. Initial RP-1 tank temperature is $530^{\circ} \mathrm{R}$. The RP-1 tank ullage pressure is 50 psia with a \pm 3 psi control range until the RP- 1 tank contains $7.58 \mathrm{lbm}$ of helium, at which time the helium mass is kept constant and the ullage is allowed to expand at a specified rate.

4. RP-1 tank pressurization line has an ID of $0.65^{\prime \prime}\left(\mathrm{OD}=0.75^{\prime \prime}\right)$, and the rest of the system has an ID of $0.83^{\prime \prime}\left(\mathrm{OD}=1^{\prime \prime}\right)$.

5. Densities of LOX and RP-1 at described conditions are $71.5 \mathrm{lbm} / \mathrm{ft}^{3}$ and 50.5 $\mathrm{lbm} / \mathrm{ft}^{3}$, respectively.

6. Volume of LOX and RP-1 tanks are $300 \mathrm{ft}^{3}$ and $188.51 \mathrm{ft}^{3}$, respectively.

7. Use available Start transient flowrate data for the first 2.5 seconds.

8. RP-1 tank initial ullage volume of $0.32 \mathrm{ft}^{3}(0.5 \%$ of total RP- 1 tank volume is $0.96 \mathrm{ft}^{3}$ which assume to fill three compartments equally).

9. LOX tank initial ullage volume is $4 \mathrm{ft}^{3}$.

10. Orifice diameter, located upstream of the RP-1 tank, is 0.18 inch.

11. Use vehicle internal environment data.

12. Duration of mainstage operation is 138 seconds. 
13. With $V^{\prime}=$ volume flowrate, $m^{\prime}=$ mass flow rate, $\rho=$ density, and $V^{\prime}=m^{\prime} / \rho$, engine requirements during the steady state engine operating period are as follows [8]:

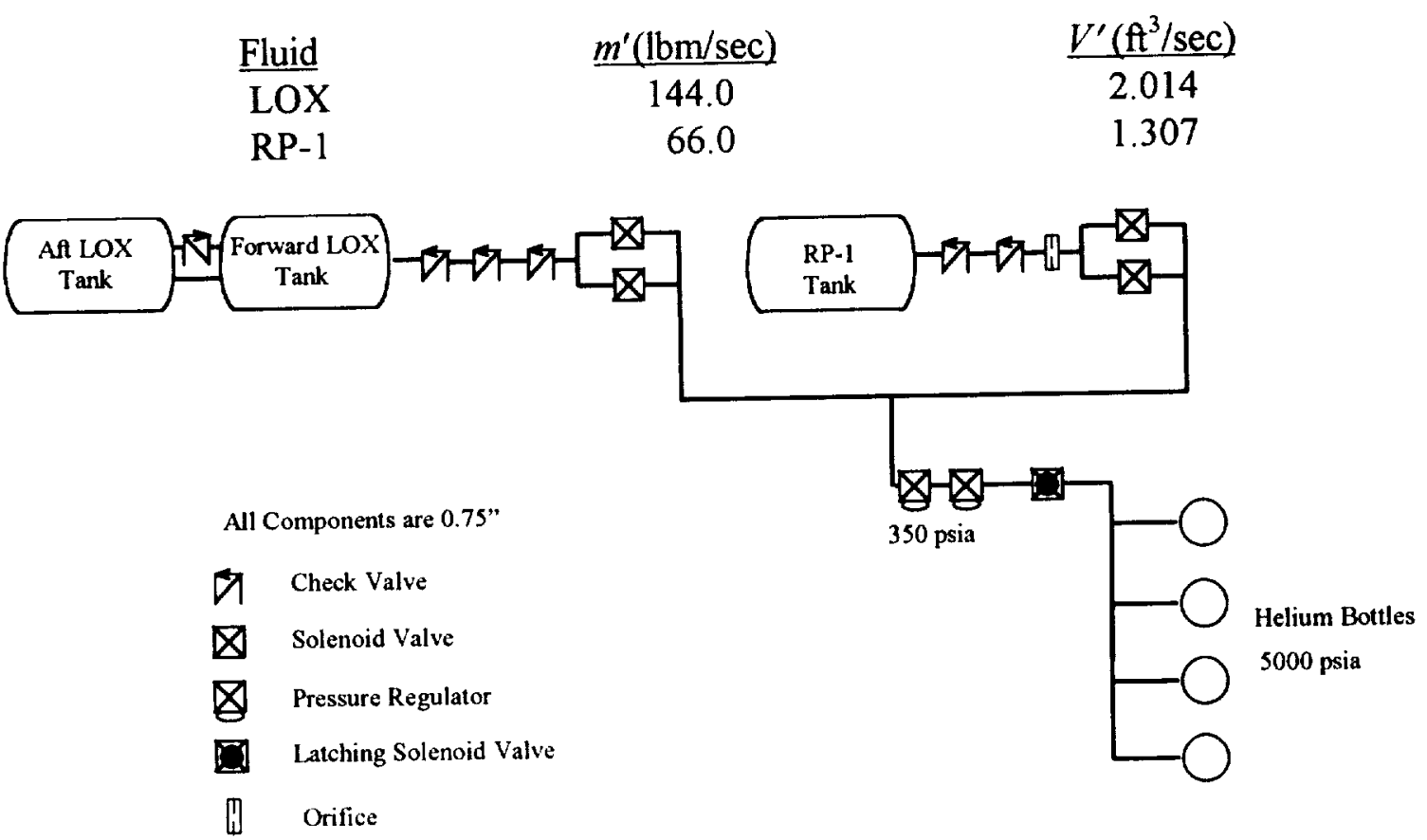

Figure 1. Pressurization System Schematic

The ROCETS ${ }^{7}$ model contains heat transfer mechanisms for the helium bottles, helium lines, and propellant tanks. The response time of the solenoid valves and control system are also modeled. The delay from the instant tank ullage pressure reaches the specified set-point until a signal is sent to the solenoid valve is 0.05 second. The solenoid valve closing/opening is considered to be linear. Initially the ullage pressures of the LOX and RP-1 tanks are 62 psia and 53 psia, respectively.

The initial stored helium mass is $76 \mathrm{lbm}$ at $530^{\circ} \mathrm{R}$ and 5000 psia. During the ground operations and captive carry periods, stored helium temperature and pressure drop to $501^{\circ} \mathrm{R}$ and 4726 psia due to significant temperature reduction due to the vehicle internal environment.

The ROCETS model was run for three diferrent cases. In the first case, the regulator exit pressure is considered to be 350 psia. Figure 2 depicts the stored helium mass history during the pressurization. The residual helium mass at the end of the pressurization process is approximately $25.4 \mathrm{lbm}$. The pressure history of the stored helium is shown in Figure 3. At the end of the process, the helium pressure is approximately 822 psia. The temperature history of the stored helium is illustrated in Figure 4. At the end of the pressurization, the helium temperature is approximately $250^{\circ} \mathrm{R}$. The LOX ullage pressure history is shown in Figure 5. The LOX tank was maintained at 65 psia with a \pm 3 psi control range. The LOX ullage pressure reaches a maximum of 68.7 psia after 1.36 
seconds. The LOX tank ullage mass history is depicted in Figure 6. This indicates that at the end of the pressurization process, the LOX tank contains $42.9 \mathrm{lbm}$ of helium.

Figure 7 shows the pressure history of the ullage within the RP-1 tank. Initially, the ullage pressure is 53 psia. The ullage reaches a maximum of approximately 54.7 psia after 2.52 seconds. After 114 seconds, the RP-1 tank contains $7.58 \mathrm{lbm}$ of helium as shown in Figure 8. At this point, the solenoid valves are closed and the ullage mass is kept constant until the end of the engine burn. At the end of the pressurization process, the RP- 1 tank ullage pressure is 39.3 psia.

For the second case, the regulator exit pressure is set at 314 psia. The LOX tank ullage pressure is illustraed in Figure 9. The LOX tank ullage pressure range for this case is 68.7 to 61.7 psia. Figure 10 depicts the RP-1 tank ullage pressure during mainstage operation. The RP-1 ullage pressure range is between 54.5 and $46.6 \mathrm{psia}$, therefore, the pressurization system provides sufficient helium supply to both propellant tanks within the specified operational pressure range. The cycle times are longer and number of cycles is less than those of the first case.

In the third case, the regulator exit pressure is set at 401 psia. Figure 11 shows the LOX tank ullage pressure history. The LOX tank maximum ullage pressure is 68.7 psia and occurs at 1.2 second. Figure 12 provides the RP-1 tank ullage pressure history. The pressure range is between 54.5 and 46.6 psia. The maximum ullage pressure is at 2.64 seconds. In this case the cycle times are the shortest while the number of cycles is the highest of the three cases.

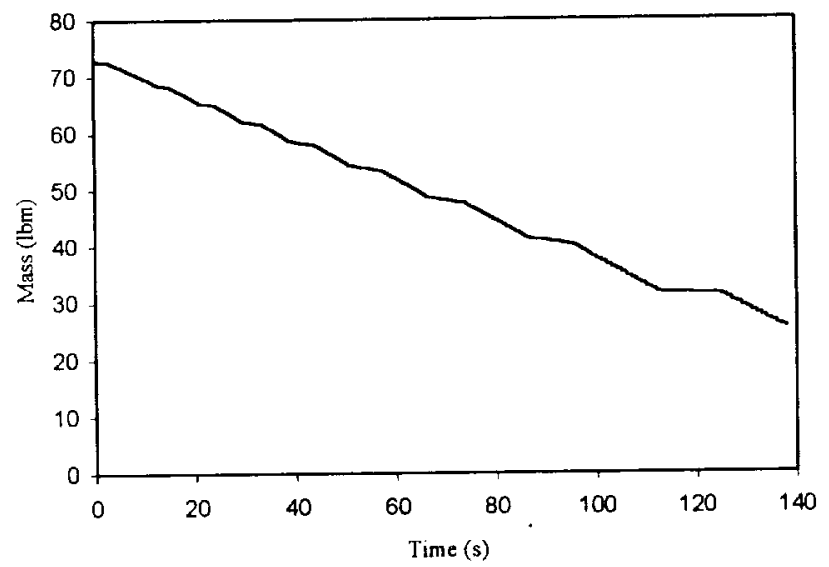

Figure 2. Stored Helium Mass History

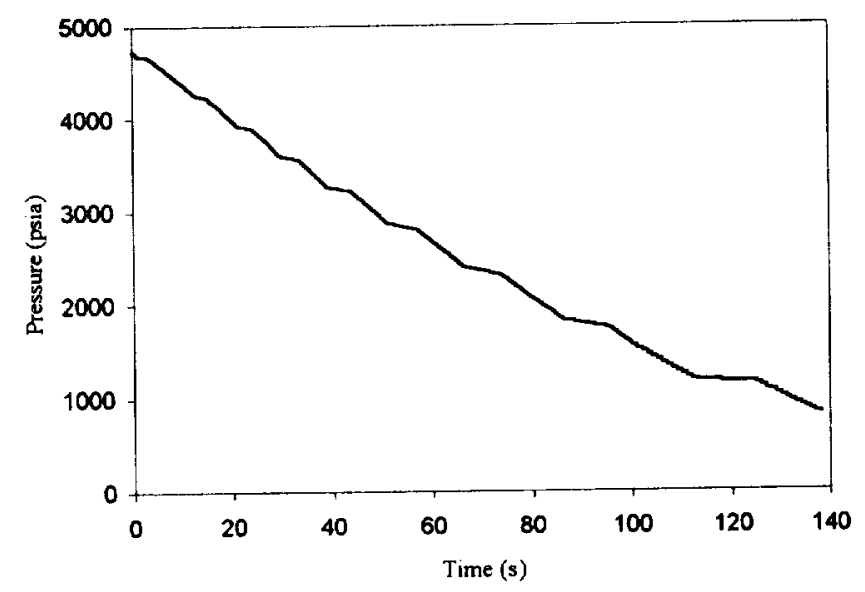

Figure 3. Pressure History of Helium Bottles 


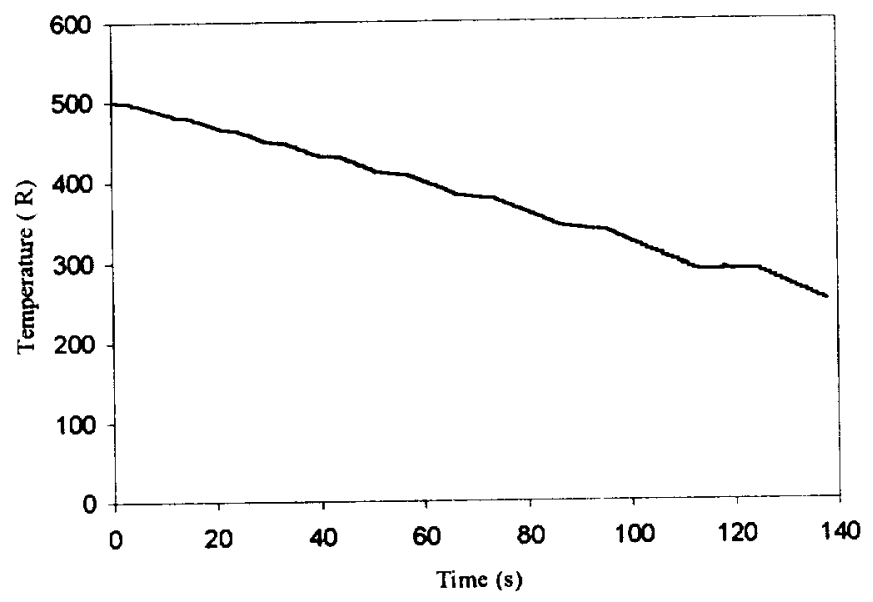

Figure 4. Stored Helium Temperature History

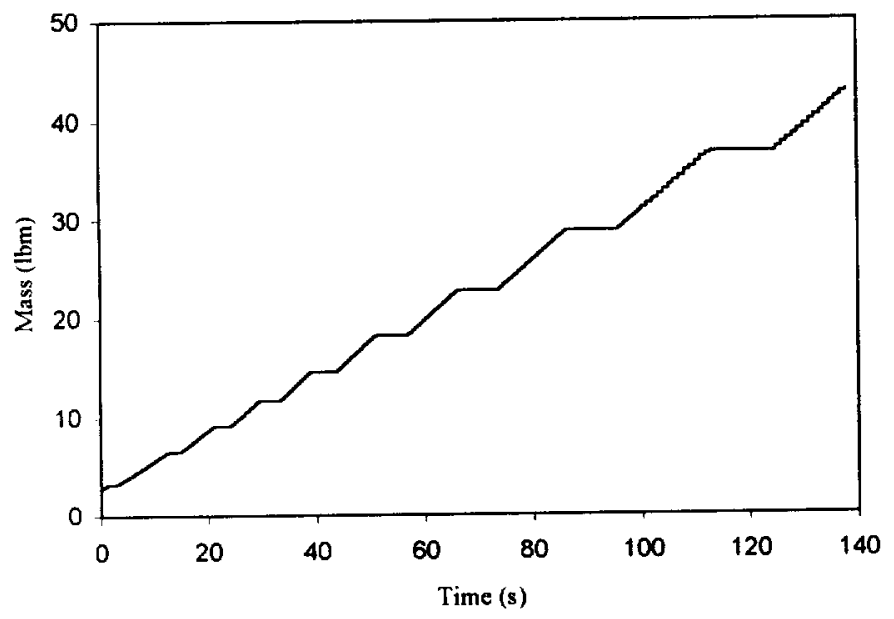

Figure 6. LOX Tank Helium Mas History

(Regulator Exit Pressure $=350$ psia)

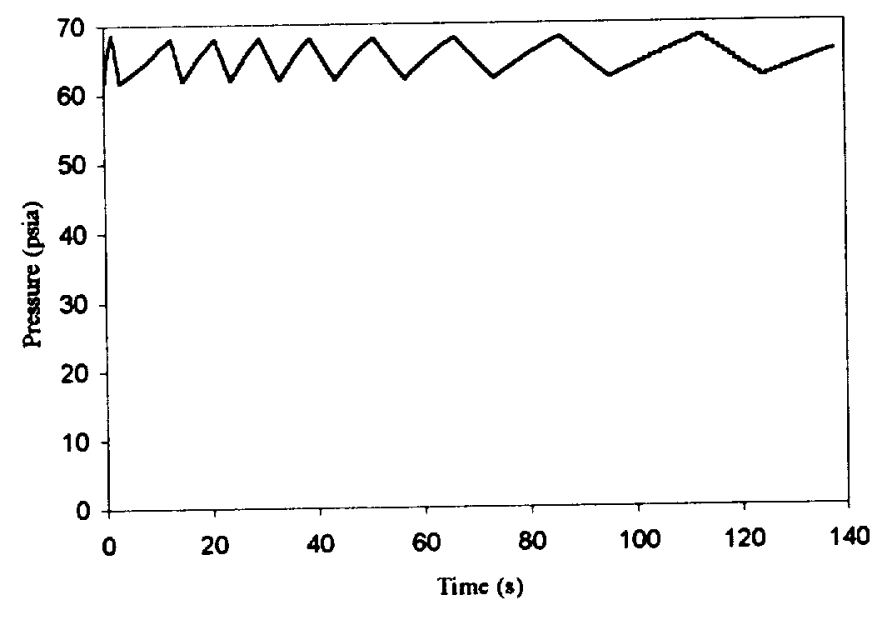

Figure 5. LOX Tank Pressure History

(Regulator Exit Pressure $=350$ psia)

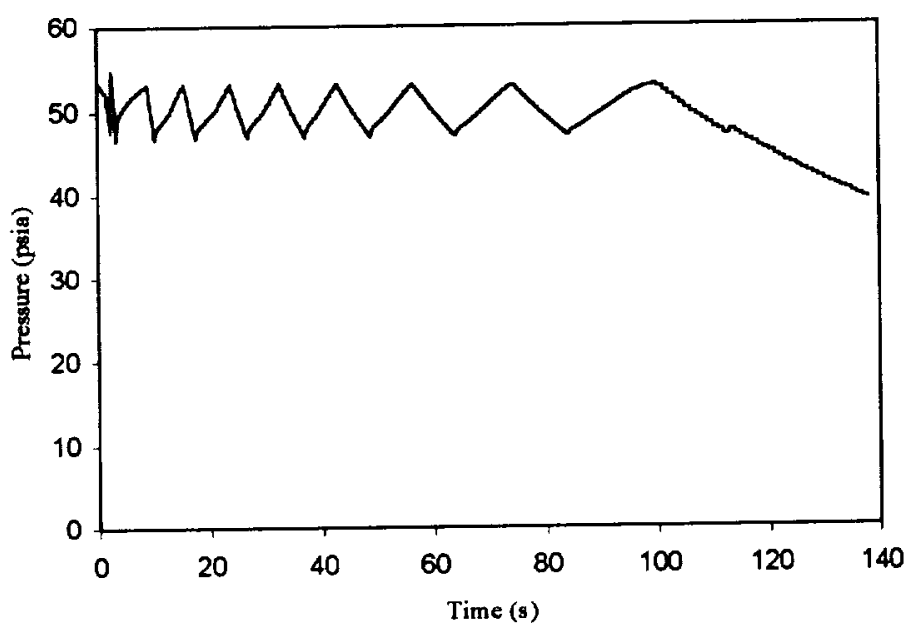

Figure 7. RP-1 Tank Pressure History

(Regulator Exit Pressure $=350$ psia) 


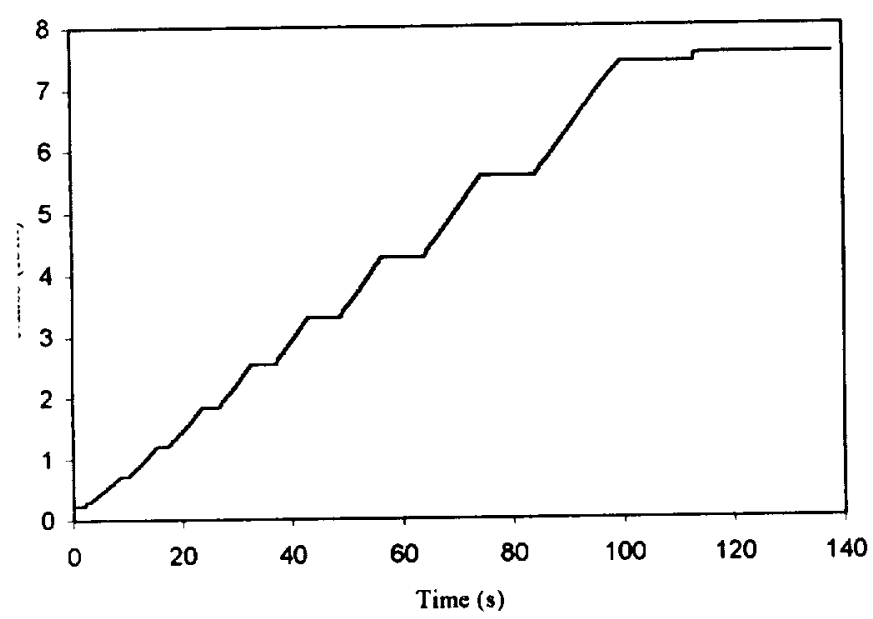

Figure 8. RP-1 Tank Helium Mass History

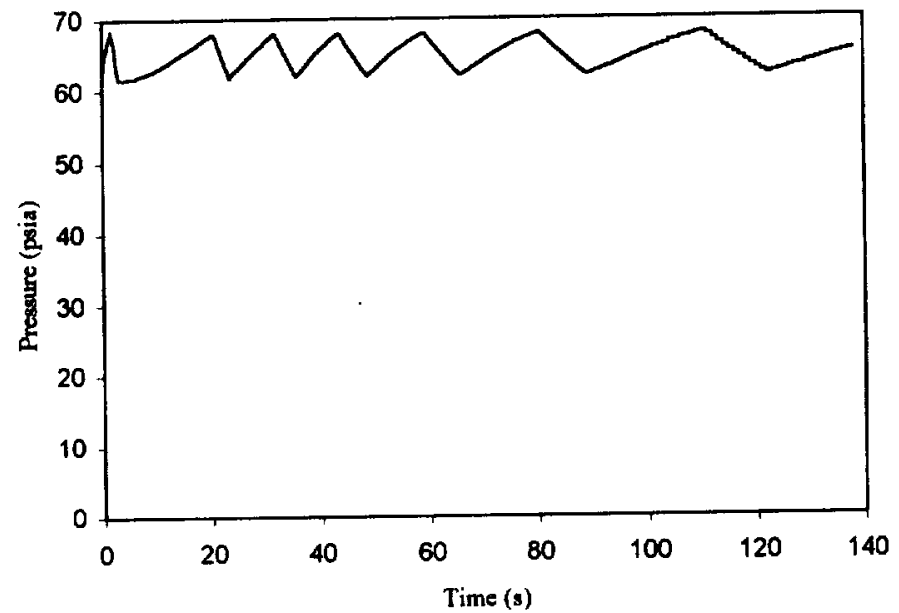

Figure 9. LOX Tank Pressure History (regulator Exit Pressure 314 psia)

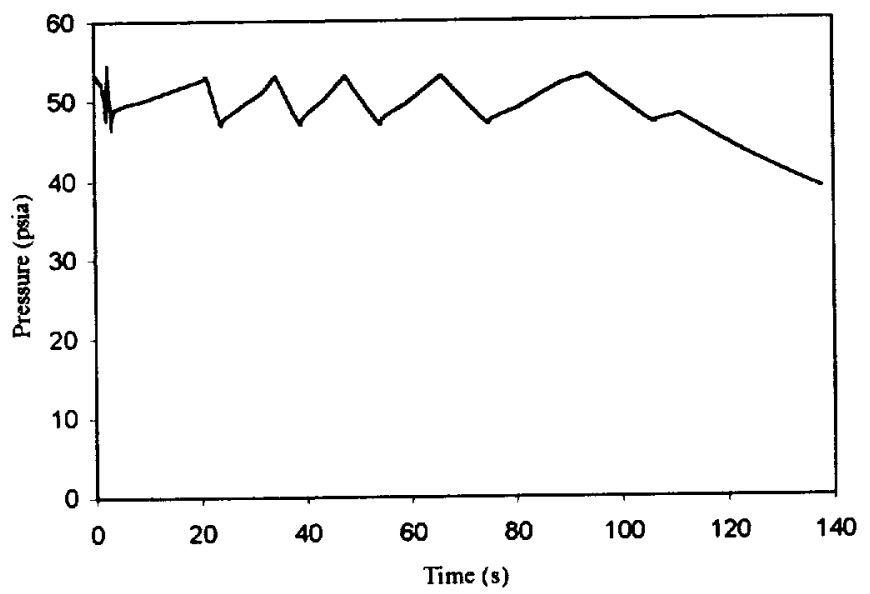

Figure 10. RP-1 Tank Pressure History

(Regulator Exit Pressure = 314 psia) 


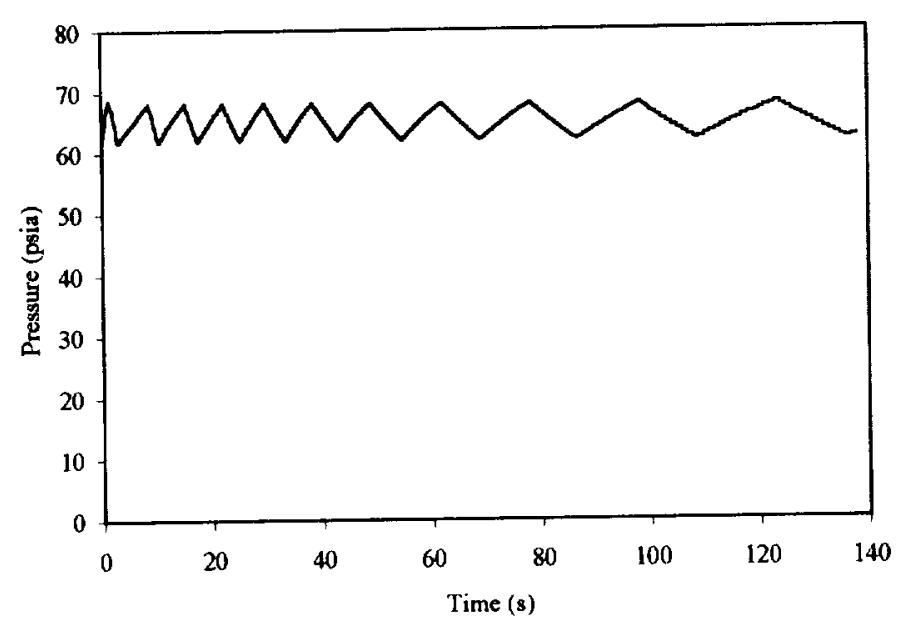

Figure 11. LOX Tank Pressure History (Regulator Exit Pressure $=401$ psia)

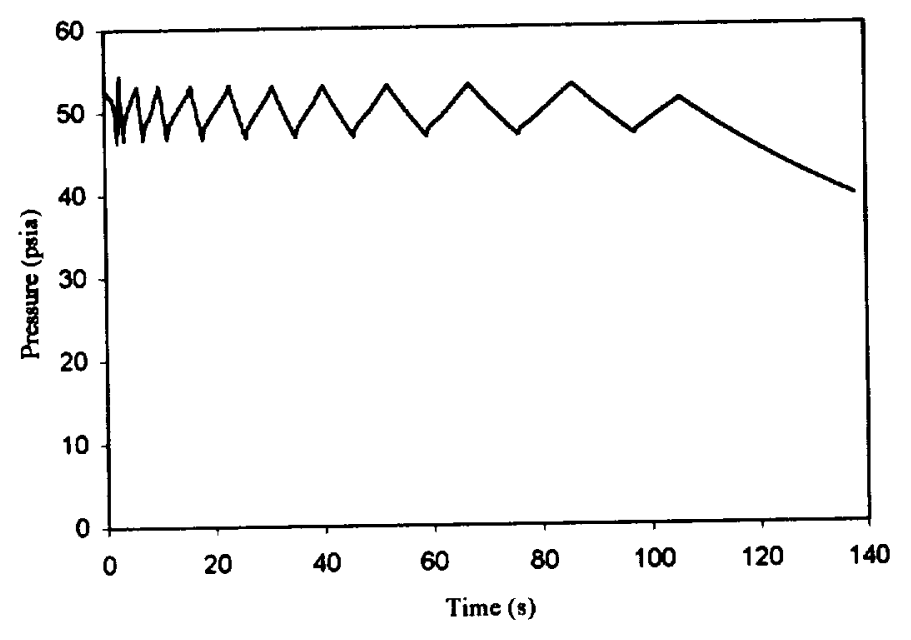

Figure 12. RP-1 Tank Pressure History (Regulator Exit Pressure $=401$ psia)

\section{PROPELLANT TANKS VENT/RELIEF SUBSYSTEM ANALYSIS}

In the event of a pressurization system solenoid valve(s) failure (fail open scenario), the propellant tanks would have a potential risk of overpressurization. The overpressurization could result in structural failure. The Vent/Relief (V/R) system on the propellant tank is intended to relieve the ullage without allowing the tank pressure to rise above proof. To evaluate the performance of the V/R system and to verify the requirements for the test data conditions, the analyses were carried out for the regulator exit pressure of 350 and 401 psia. Simultaneous operation of the pressurization and V/R systems, and performance of the V/R system, were simulated using ROCETS. The ROCETS model simulated the potential tank overpressurization due to failure of the solenoid located upstream of the tank and the response of the $V / R$ system.

If the solenoid valves fail open, the continuos flow of helium and its accumulation in the tank lead to pressure build up and eventually potential overpressurization of the tank. As the pressure reaches a specified value, the $V / R$ valve is opened to allow ullage to leave, therefore, relieving the pressure. In addition to assumptions provided in Pressurization Subsystem Analysis section, to simulate the solenoid valve(s) failure and to evaluate the potential tank overpressurization, the following assumptions were made:

1. The 2.5 " Main V/R valve has a relief capacity of a 1.5 " equivalent sharp-edged orifice diameter (eseod) with a discharge coefficient of 0.60 . The response time for a complete cycle is 0.14 second (i.e., as tank pressure reaches 88 psia, 0.14 second later the valve is fully open).

2. By-pass V/R valves are similar with eseod of $0.35^{\prime}$, and a discharge coefficient of 0.6 . The cracking pressure is 85 psia and the valve is fully open at a tank 
pressure of 98 psia (assume valve area variation is a linear function of tank pressure, i.e., at pressure less than or equal to $85 \mathrm{psia}$, the area is zero; and as the tank pressure reaches $98 \mathrm{psia}$, the valve is fully open).

3. No RP-1/LOX outflow from the tank.

4. Both propellant tanks have a proof pressure of 112.5 psia.

In this analysis, the failure of the solenoid valves (fail-open scenario) was simulated by ROCETS for 2 different cases. For the first case, the regulator exit pressure was considered to be at 350 psia. For the second case, a maximum of 401 psia was applied at the regulator exit. For both simulation cases, the boundary conditions and thermodynamic states are assumed to be the same.

For the cases in which the Main V/R valve is operating, as the propellant tank reaches 88 psia a delay equivalent to 0.14 second is imposed, then the Main $V / R$ valve is set to open fully, allowing the ullage to exit. As the ullage discharges from the tank, the pressure within the tank drops. When the ullage pressure drops below 75 psia, the Main V/R valve is closed. For the By-pass V/R valve(s) operational scenario, the valve cracking pressure is set to $85 \mathrm{psia}$, and the valve(s) is (are) fully open as the tank pressure reaches $98 \mathrm{psia}$.

Figure 13 depicts the RP- 1 tank ullage pressure history where regulator exit pressure is assumed to be $350 \mathrm{psia}$. As the helium enters the tank, the tank pressure rises. When the tank pressure reaches 85 psia, the By-pass $V / R$ valve begins to open and when the pressure reaches 98 psia, the By-pass valve is fully open. The By-pass $V / R$ valve area is assumed to be a linear function of the tank pressure. So, at the tank pressure equal (or less than) to 85 psia, the valve area is set to zero, while at the tank pressure of 98 psia (or higher), the valve is $100 \%$ open. In addition, 0.14 second after the tank reaches 88 psia, the Main V/R valve is fully open. As the Main V/R valve opens, the ullage is allowed to relieve at a greater rate. As the tank pressure drops below 85 psia, the By-pass $V / R$ valve closes while the Main $V / R$ valve is open until the tank pressure drops below 75 psia, at which point the Main V/R valve also is closed. The maximum RP-1 tank pressure is about 98 psia.

The LOX tank pressure history for regulator exit pressure of 350 psia is shown in Figure 14. The LOX Main V/R operation is similar to that of the RP-1 tank. As pressure reaches 88 psia, a valve response time of 0.14 second is applied. So, as the tank pressure reaches $88 \mathrm{psia}, 0.14$ second later the Main V/R valve is fully open and the ullage is allowed to leave, therefore relieving the tank pressure. As the tank pressure drops below $75 \mathrm{psia}$, the Main V/R valve is closed. For this scenario, the maximum LOX tank ullage pressure is 101 psia

Figure 15 illustrates the RP-1 tank pressure history for the regulator exit pressure of 401 psia. The maximum tank ullage pressure is 98 psia. Figure 16 depicts the LOX tank ullage pressure history for the regulator exit pressure of 401 psia. Maximum ullage pressure for this case is 106 psia. 
In all of the above described cases, the maximum RP-1 or LOX tank ullage pressure is below the proof pressure of 112.5 psia.

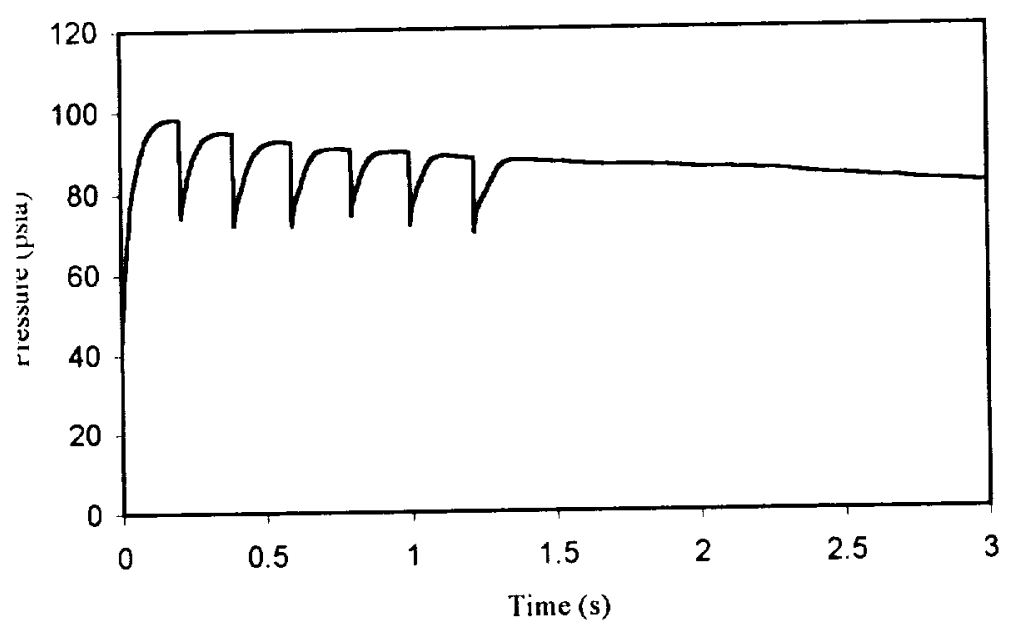

Figure 13. RP-1 Tank Ullage Pressure History (Regulator Exit Pressure $=350$ psia)

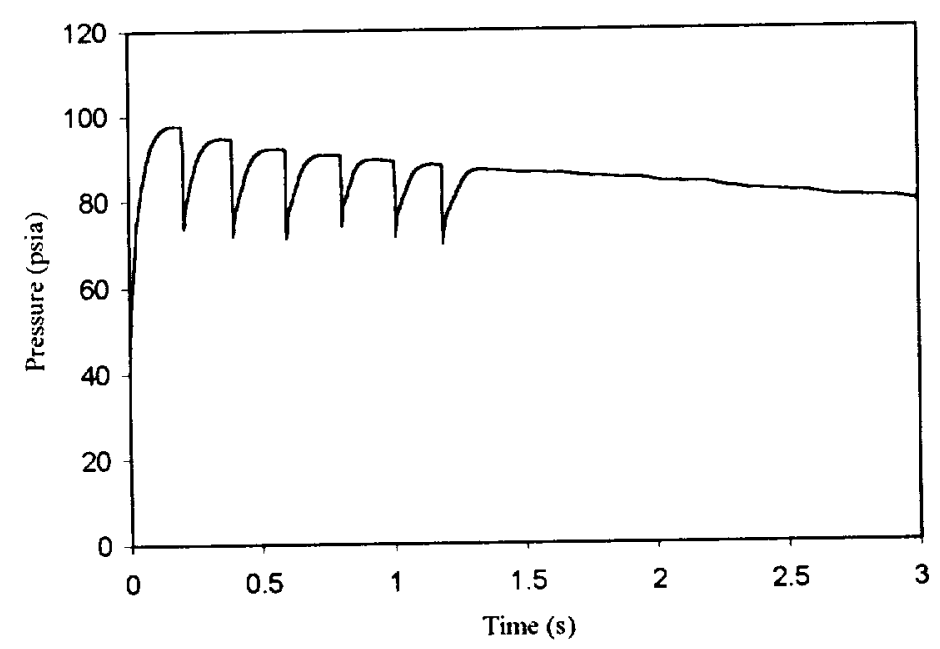

Figure 15. RP-1 Tank Ullage Pressure History (Regulator Exit Pressure $=401$ psia)

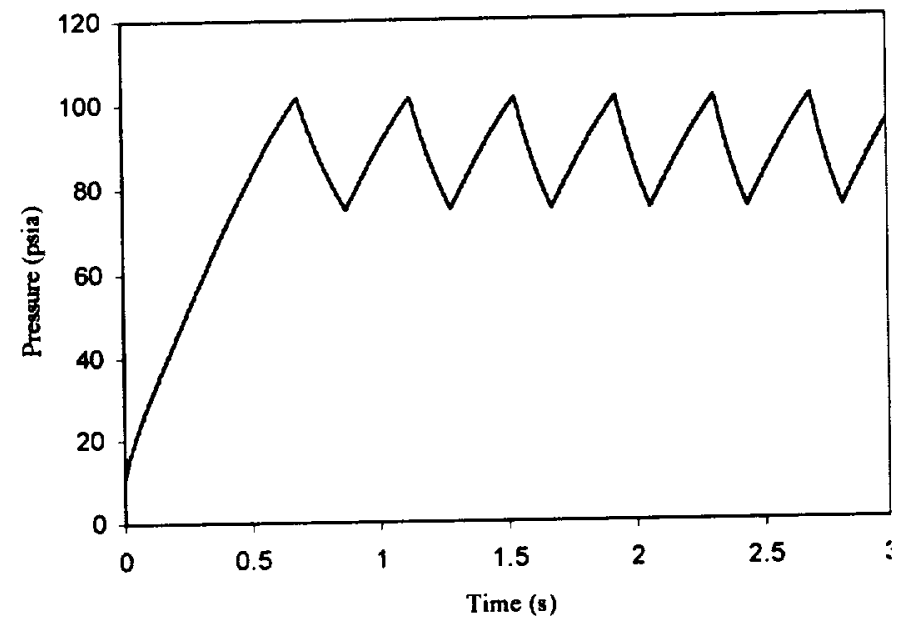

Figure 14. LOX Tank Ullage Pressure History (Regulator Exit Pressure $=350$ psia)

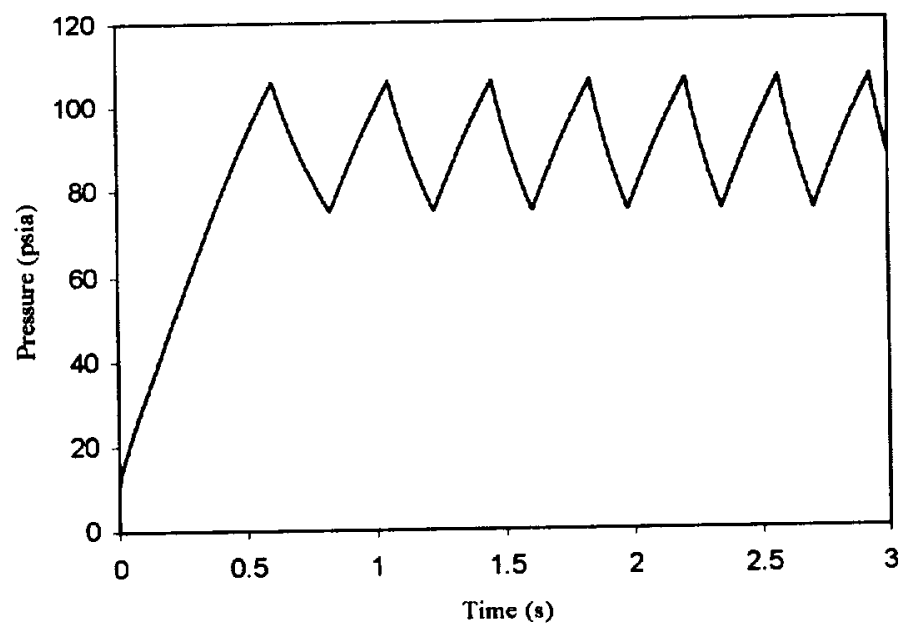

Figure 16. LOX Tank Ullage Pressure History (Regulator Exit Pressure $=401$ psia) 


\section{PNEUMATIC SYSTEM ANALYSIS}

The pneumatic system is used for pneumatic valve actuation, Inter-Propellant Seal (IPS) purges, engine Spin Start, and other engine purges. The helium pressure is regulated prior to its use as a working fluid. The engine Spin Start process requires a high flow of helium through the turbine to drive the pump during the engine start transient. The IPS purge is required whenever propellants are provided to the engine to assure separation of RP-1 and LOX in the single-shaft pump of the Fastrac engine. The pneumatic system operation was simulated using ROCETS.

A schematic of the pneumatic system is shown in Figure 17. For the ROCETS transient analysis of the pneumatic system, the following assumptions are made:

1. Initial helium temperature and pressure at ground loading are $530{ }^{\circ} \mathrm{R}$ and 5000 psia.

2. Helium usage for Spin provides $70-72 \mathrm{hp}$ power at Spin Start .

3. At the end of Captive Carry, for the large bottle: pressure $=4726$ psia, temperature $=501^{\circ} \mathrm{R}$; for the small bottles: pressure $=4100 \mathrm{psia}$, temperature $=$ $434^{\circ} \mathrm{R}$.

4. Volumes of large and small bottles are $6.2 \mathrm{ft}^{3}$ and $2.2 \mathrm{ft}^{3}\left(1.1 \mathrm{ft}^{3} /\right.$ bottle $)$, respectively.

5. Initial helium masses for the one large and two small bottles are 19 and $7.3 \mathrm{lbm}$ $(3.65 \mathrm{lbm} /$ bottle), respectively.

6. Average helium flowrate for the IPS purge $=0.007 \mathrm{lbm} / \mathrm{s}$.

7. Pressure at the pump inlet $\geq 115$ psia.

8. The turbo-pump helium passages are considered as orifices with the following flow characteristics: for RP-1 side, flow coefficient $(C d)=0.7$, area $=0.005 \mathrm{in}^{2}$; for LOX side, $\mathrm{Cd}=0.5$, area $=0.003 \mathrm{in}^{2}$.

9. Model duration (-900) to (1955) seconds (engine start @ time =0).

Initially, the forward and aft bottles hold a total of $26.3 \mathrm{lbm}$ of helium at $5000 \mathrm{psia}$ and $530^{\circ} \mathrm{R}$. The regulator in the IPS line reduces the pressure to 175 psia while the regulators in the Spin Start and purge lines provide pressures of 1050 psia and 750 psia, respectively. 


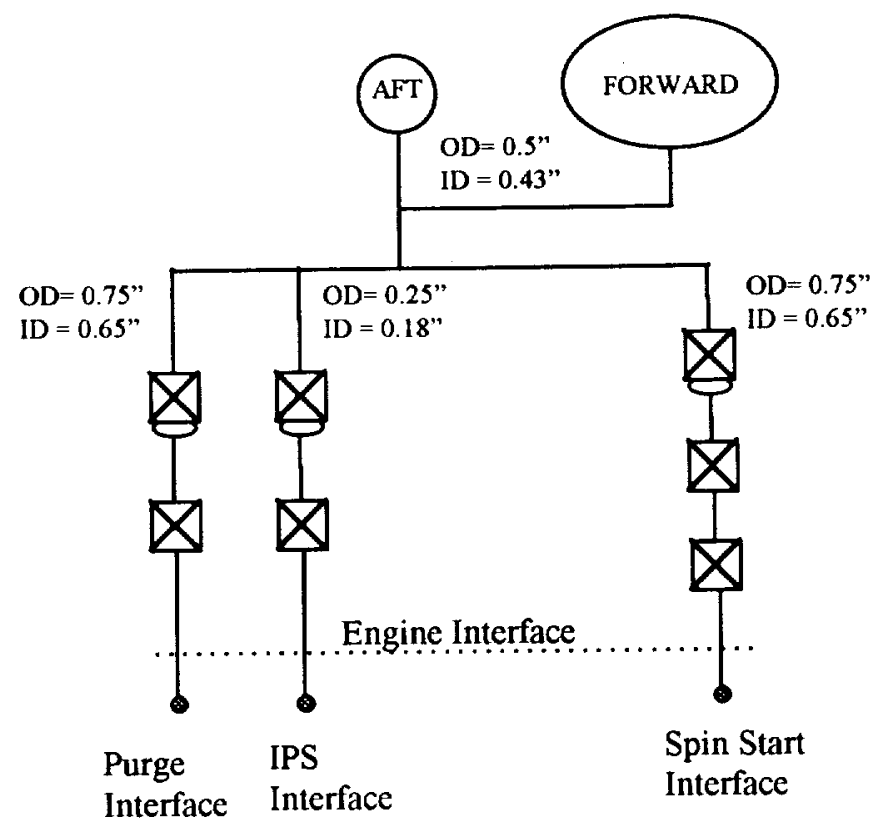

Q Solenoid Valve Pressure Regulator

Figure 17. Pneumatic System Schematic

To supply helium to the pump cavity at a pressure above $115 \mathrm{psia}$, the exit pressure of the regulator is set to a constant value of 175 psia. Figure 18 depicts the IPS helium flowrate history. Initially, a flowrate of $0.0068 \mathrm{lbm} / \mathrm{s}$ is provided at the IPS, but the helium density increases as the helium temperature drops. Therefore, the mass flowrate to the IPS increases to $0.0078 \mathrm{lbm} / \mathrm{s}$ by the end of the mission. Figure 19 illustrates the pressure history at the pump cavity inlet. The cavity pressure is kept above 115 psia and reaches 136 psia at the completion of the simulation.

Helium usage is illustrated in Figure 20. For the IPS purge, Spin Start, and engine purges, helium consumption is $20.3,3.0$, and $1.86 \mathrm{lbm}$, respectively. Therefore, the total helium consumption is $25.2 \mathrm{lbm}$. The stored helium mass history is shown in Figure 21. Initially, the total stored mass is $26.3 \mathrm{lbm}$. At the completion of the simulation, the residual helium masses in the large and small bottles are $0.52 \mathrm{lbm}$ and $0.47 \mathrm{lbm}$, respectively. Figure 22 depicts the Spin Start power. The power range is $71-78 \mathrm{hp}$, which meets the projected values of 70-72 hp. 


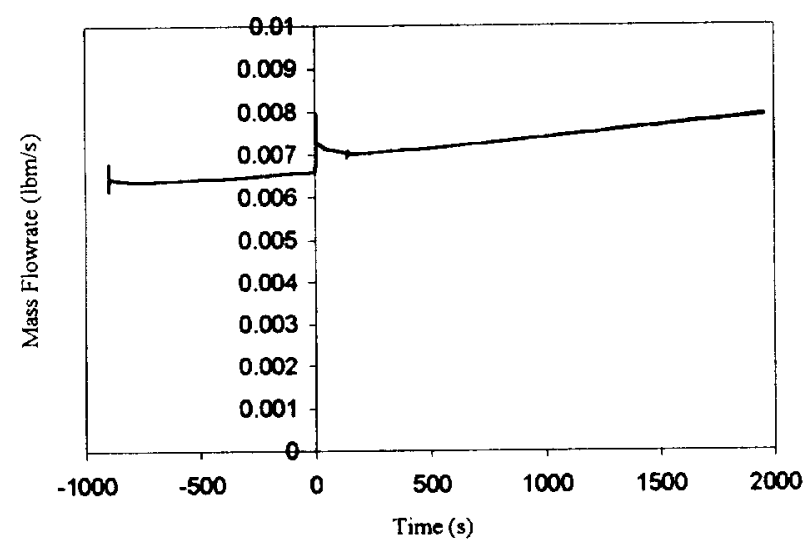

Figure 18. Helium Flowrate for the IPS Purge

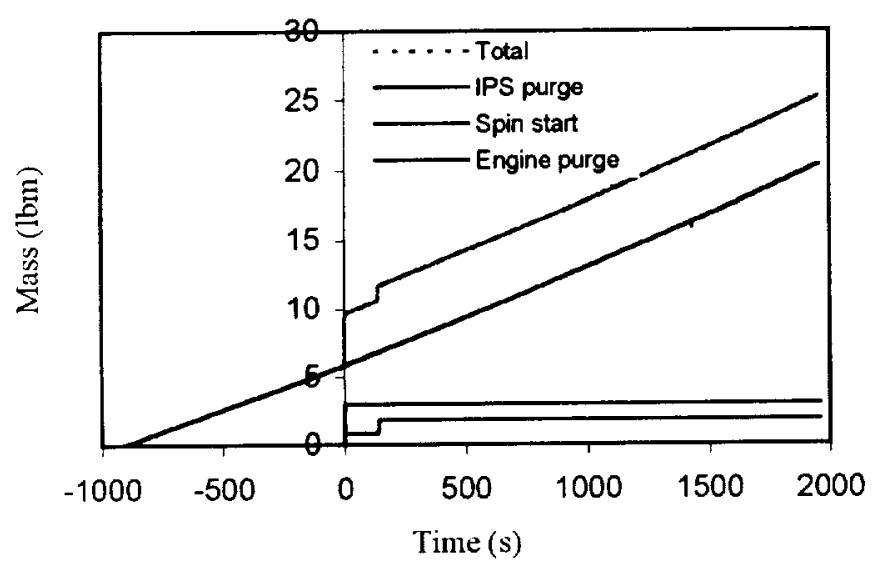

Figure 20. Helium Mass Used

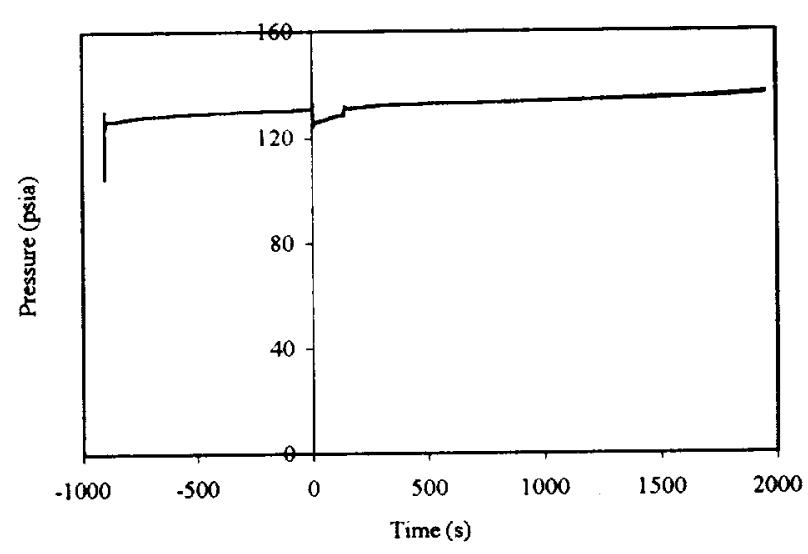

Figure 19. Pump Cavity Pressure History

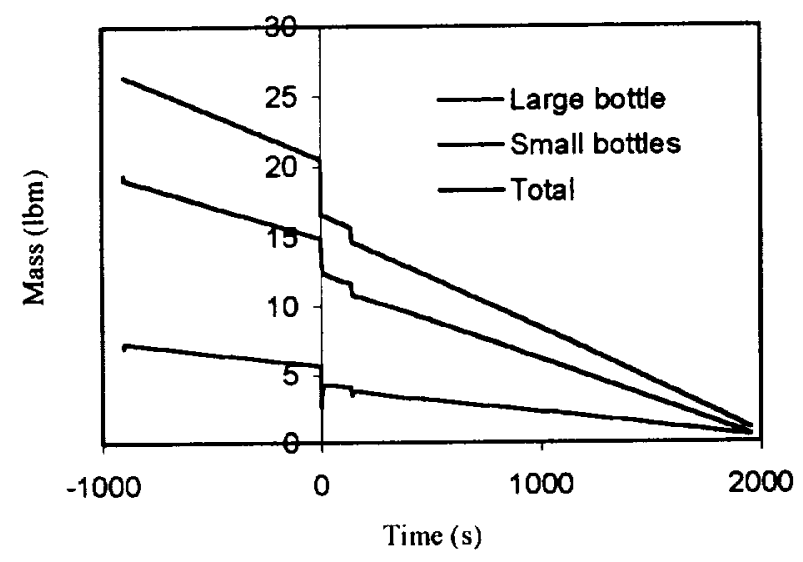

Figure 21. Stored Helium Mass 


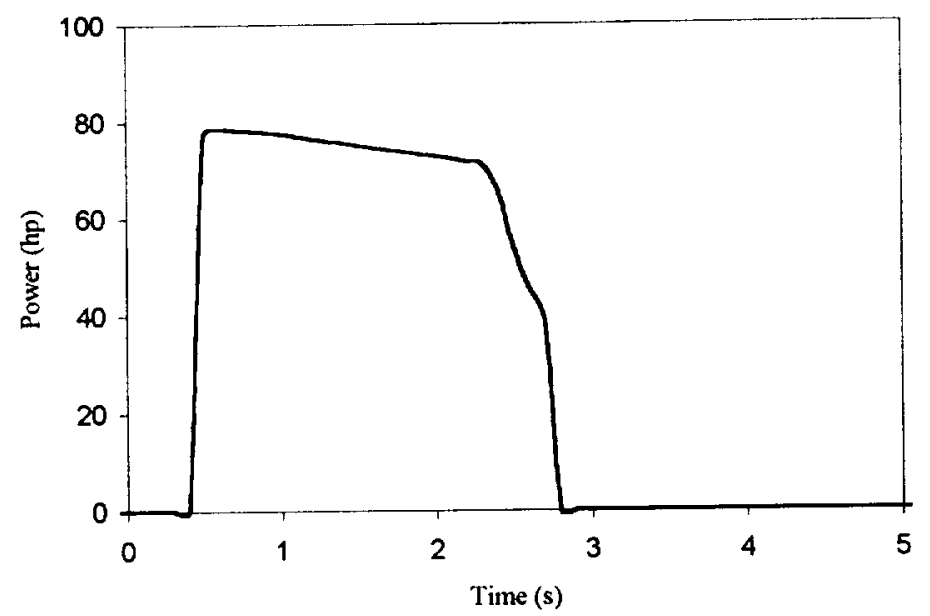

Figure 22. Spin Start Power

\section{ACRONYMS AND ABBREVIATIONS}

$\begin{array}{ll}\text { eseod } & \text { Equivalent-Sharp-Edged-Orifice-Diameter } \\ \mathrm{ft} & \text { Foot } \\ \mathrm{He} & \text { Helium } \\ \mathrm{hr} & \text { Hour } \\ \mathrm{ID} & \text { Inside Diameter (in) } \\ \mathrm{IPS} & \text { Inter-Propellant Seal } \\ \text { LOX } & \text { Liquid Oxygen } \\ \text { MPS } & \text { Main Propulsion System } \\ \text { OD } & \text { Outside Diameter (in) } \\ \text { ROCETS } & \text { ROCket Engine Transition Simulation } \\ { }^{\circ} \mathrm{R} & \text { Degree Rankine } \\ \text { RP-1 } & \text { Rocket Propellant 1 } \\ \text { psia } & \text { Pound Per Square Inch Absolute } \\ \text { S } & \text { Second }\end{array}$




\section{REFERENCES}

1. Sgarlata, P. and Winters, B., (1997), "X-34 Propulsion System Design," AIAA paper No., AIAA-97-3304.

2. Champion, R. H., Jr., and Darrow, R. J., Jr., (1998), "X-34 Main Propulsion System Design and Operation,", AIAA paper No. AIAA-98-4032.

3. Brown, T. M., McDonald, J. P., Hedayat, A., Knight, K. C., and Champion, R. H. Jr., (1998), "Propellant Management And Conditioning Within the X-34 Main Propulsion System," AIAA paper No., AIAA-98-3518.

4. Hedayat, A., Steadman, T. E., Brown, T. M., Knight, K. C., White, C. E., Jr., and Champion, R. H., Jr., (1998), "Pressurization, Pneumatic, and Vent Subsystems of the X-34 Main Propulsion System," AIAA paper No. AIAA-98-3519.

5. McDonald, J. P., Minor, R. B., Knight, K. C., Russell, F. J., Jr., and Champion, R. H., Jr., (1998), "Propellant Feed Subsystem for the X-34 Main Propulsion System," AIAA paper No. AIAA-98-3517.

6. McDonald, J. P., Hedayat, A., Brown, T. M., Knight, K. C., and Champion, R. H., Jr., (1998), "Subsystem Analysis/Optimization for the X-34 Main Propulsion System,"

7. “ROCETS User's Manual," Pratt and Whitney, West Palm Beach, FL, January 1995. 